\title{
Special Issue on Genome Editing
}

\author{
David Songstad ${ }^{1}$
}

Accepted: 3 August 2021 / Published online: 4 October 2021 / Editor: David Songstad

(c) The Society for In Vitro Biology 2021

This "Special Issue on Genome Editing" is dedicated to plant genome editing and has a beginning dating back to 2013. This is the year when the first CRISPR/Cas9 presentations occurred at the Society for In Vitro Biology (SIVB) meeting in Providence, Rhode Island. In each of the years that followed, there have been a plethora of symposia, workshops, and oral or poster presentations on genome editing. In 2018, while serving the society as the Program Chair for the SIVB annual meeting in Saint Louis, Missouri, the meeting was focused on highlighting genome editing. For this reason, I invited Dr. Rachel Haurwitz (President and CEO of Caribou Biosciences) to be the 2018 SIVB Keynote Speaker (Fig. 1). The 2018 annual meeting invigorated interest to organize a Special Issue on Genome Editing. The initial attempts to accomplish this were led by the Past Editor in Chief, Dr. David Duncan. His efforts were followed by those of the current Editor in Chief, David Songstad, who assembled a team to help with the organization and delivery of this Special Issue. This team was formed in 2019 when two Associate Editors, Dr. John Chen and Dr. Prakash Lakshmanan, agreed to dedicate time and effort to work with the Editor in Chief on this Special Issue of In Vitro Plant. The three of us worked together previously on the very wellreceived 2009 Special Issue on Biofuels that appeared in In Vitro Plant so our plans were to replicate the process that we had already developed. A Guest Associate Editor, Dr. Gary Bannon, was enlisted and his help was extremely valuable and it was a pleasure to have him on our team. This Special Issue has fifteen manuscripts on various topics covering plant genome editing. A special and sincere thank you goes to all of the authors, both corresponding authors and co-authors, for their time, effort, and diligent outcomes that resulted in these outstanding manuscripts. Without your support and contributions, this Issue of In Vitro Plant would not have happened. A very special "Thank You" goes to Dr. Albert Kausch, University of Rhode Island, for the handdrawn artwork that appears on the cover of this issue of In Vitro Plant illustrating the similarities between zygotic and somatic embryogenesis with utility in genome editing research.

Respectfully submitted,

David Songstad, PhD

Editor in Chief

In Vitro Cellular \& Developmental Biology - Plant

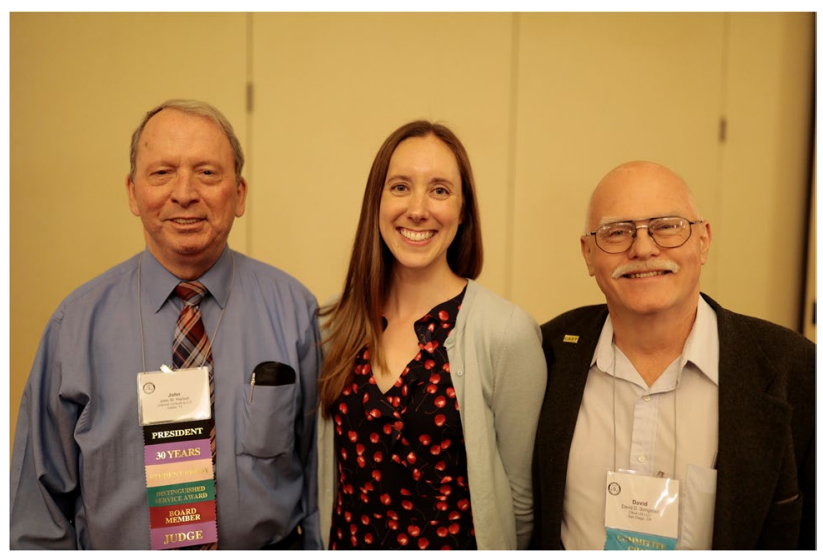

Figure 1. Dr. John Harbell, Past President Society for In Vitro Biology (SIVB), Dr. Rachel Haurwitz, President and CEO of Caribou Biosciences, and Dr. David Songstad, Past President of SIVB, 2018 SIVB Program Chair and current Editor-in-Chief of In Vitro - Plant at the 2018 SIVB meeting in Saint Louis, Missouri. Credit: Society for In Vitro Biology for the permission to use this photo.
David Songstad

davidsongstad@aol.com

1 Songstad Consulting, San Marcos, CA, USA 